\title{
Management Patterns of Delayed Inflammatory Reactions to Hyaluronic Acid Dermal Fillers: An Online Survey in Israel
}

This article was published in the following Dove Press journal: Clinical, Cosmetic and Investigational Dermatology

\author{
Dana Shalmon' \\ Joel L Cohen ${ }^{2}$ \\ Marina Landau (iD) ${ }^{3}$ \\ Ines Verner ${ }^{4}{ }^{4}$ \\ Eli Sprecher ${ }^{1,5}$ \\ Ofir Artzi (iD)
}

'Department of Dermatology, Tel Aviv Sourasky Medical Center, Tel Aviv, Israel; ${ }^{2}$ AboutSkin Dermatology and AboutSkin Research, Greenwood and Lone Tree, CO, USA; ${ }^{3}$ Private Practice, Herzliya, Israel; ${ }^{4}$ Verner Clinic Tel Aviv, University of Rome "Guglielmo Marconi", Israel, Italy; ${ }^{5}$ Department of Human Molecular Genetics \& Biochemistry, Sackler Faculty of Medicine, Tel Aviv University, Tel Aviv, Israel
Correspondence: Ofir Artzi Email ofira@tlvmc.gov.il
Background: Over the past few decades, soft tissue augmentation is ever-increasing, specifically hyaluronic acid (HA)-based filler injections. As the number of these procedures have risen, so have the adverse reactions. Delayed-type inflammatory reactions (DIRs) secondary to tissue fillers are typically classified according to the time of appearance postprocedure and have various presentations including nodules, abscesses, edema, and discoloration. Currently, the treatment of these complications varies among physicians.

Objective: The aim of this study was to assess the knowledge and experience of practitioners in Israel who inject HA-based tissue fillers with respect to the management of lateonset procedural complications.

Materials and Methods: A survey regarding management and treatment of late-onset inflammatory reactions was sent to 1120 physicians and dentists in Israel who practice tissue filler injections.

Results: Three hundred thirty-four out of the 1120 practitioners replied to the questionnaire. The majority of respondents were dentists (group A) comprising 31\% of all respondents. Group B accounted for $31 \%$ of injectors and consisted of dermatologists (19\%) and plastic surgeons $(12 \%)$, and group C (38\%) accounted for all other practitioners; $48.2 \%$ of all injectors indicated that they have not previously encountered a DIR, whereas $11.4 \%$ responded that they have encountered more than 5 DIRs. In order to assess treatment management, we presented the injectors with a simulatory case of a woman with a lateonset complication. Most injectors referred the patient to the emergency department. When asked to establish a treatment plan, the majority of practitioners prescribed short-term oral steroids, ie, prednisone $(35.3 \%)$. A limited number of patients were treated with intralesional hyaluronidase (31.4\%) injection as only $34 \%$ of injectors kept hyaluronidase at their clinic.

Conclusion: The varied approach regarding the management of delayed type reactions to HA-based filler injections, reflected in our study, illustrates the existing ambivalence in the current literature regarding the management and therapy of late-onset complications.

Keywords: cosmetic techniques, dermal fillers/adverse effects, hyaluronic acid/adverse effects, delayed reaction, nodules, filler, hypersensitivity

\section{Introduction}

The popularity of injected tissue fillers as a minimally invasive aesthetic procedure for soft tissue augmentation continues to rise among individuals who wish to restore volume and gain a younger appearance. ${ }^{1}$ Its record of safety, innate biocompatibility with human tissue, and longevity ${ }^{2}$ has made cross-linked hyaluronic 
acid (HA) the most prevalent soft tissue filler in use, accounting for more than 2 million procedures in the USA in 2017. ${ }^{3}$ Delayed inflammatory reactions (DIRs) secondary to HA-based tissue fillers are often classified according to the time of appearance post-procedure ["early" ( $<14$ days), "late" ( $>14$ days to 1 year) or "delayed" ( $>1$ year)]. ${ }^{4}$ Various causes for late or delayed reactions have been proposed, such as immunogenic triggers (eg, antibodies against HA), protein impurities, HAbreakdown byproducts, foreign bodies, infections, or biofilms. ${ }^{5-8}$ Immunogenic "triggers" prior to the onset of delayed reactions, such as a flu-like illness and dental procedures, have also been proposed. ${ }^{7}$

Although the issue has been discussed and reported in the literature, there is still no consensus on the management or treatment of DIRs. The authors' objective was to assess the knowledge and proficiency in treating DIRs among injectors in Israel who perform HA-based filler injections.

\section{Methods}

\section{The Questionnaire}

An anonymous questionnaire comprised of 14 multiple choice questions regarding the management of DIRs was sent to 1120 dentists and physicians in Israel who practice tissue filler injections. The questionnaire was approved by the Tel Aviv Medical Center institutional review board in accordance with the principles of the Declaration of Helsinki. The questionnaire comprised of two specific sections.

The first section included questions on the responders' specialty, number of years practicing dermal filler injections, number of syringes used per week, number of DIRs encountered, and whether hyaluronidase was available at their clinics.

The second section aimed at assessing the responder's management of a simulated case of a healthy 46-year-old woman who weighed $70 \mathrm{~kg}$, and who presented twice to their clinic. The first encounter occurred 7 weeks post-HAbased injections to the midface and tear trough areas. A photograph (Figure 1) was included and written informed consent for the image to be published was provided by the patient. The patient complained of hardening and tenderness of the skin below the right eye, accompanied by difficulty in opening her eye. She stated that she felt well, and denied having a fever or any other systemic signs. She also denied the use of any new medication, topical remedy, preceding injury or insect bite.

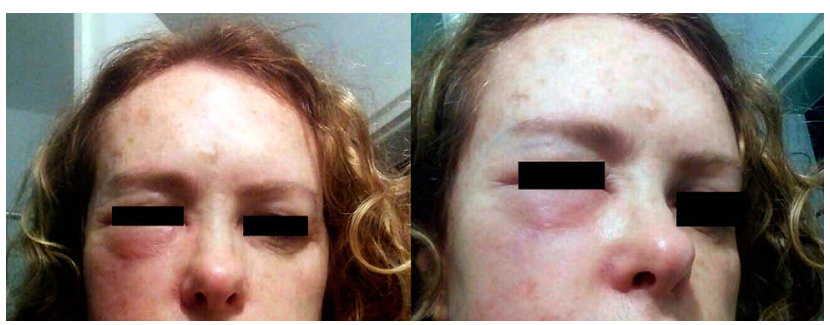

Figure I The photograph presented to responders as part of the first encounter of the simulation.

The injectors were initially asked to decide whether they would treat the patient in their own clinic, refer the patient to treatment at an emergency department (ED), or follow a watchful waiting approach. Patients referred to the ED were sent back to the injector after being discharged with the diagnosis of DIR. The responders were then asked to choose what treatment they would administer: oral antibiotics, oral corticosteroids, intralesional (IL) corticosteroids, non-steroidal anti-inflammatory drugs (NSAIDs), IL hyaluronidase, IL 5FU, topical therapy with a corticosteroid or calcineurin inhibitor, laser therapy or "other" [blank line for entering alternative option(s)].

Next, the responders who chose antibiotic therapy were asked to specify which regimen of antibiotic therapy they would prescribe. They were given the options of one or more of the following: minocycline, macrolides, ciprofloxacin, amoxicillin/clavulanic acid, and cephalexin at different dosages and different durations of therapy. Those who chose oral corticosteroid therapy were asked to specify the dosage and duration they would prescribe for prednisone. Those who chose to treat via IL hyaluronidase were asked to indicate dose in units. All questions had an option to answer "other" where the responders could add their own text.

The second encounter took place several weeks after the initial treatment, as the patient returned complaining of an exacerbation. A photograph was included and she was clinically diagnosed with a DIR.

The responders were once again asked to decide whether they would treat the patient at their clinic, refer the patient for treatment at an ED, or choose a watchful waiting approach. As before, patients referred to the ED were sent back to the injector after being discharged with the diagnosis of DIR, and the responders were asked to choose how they would treat the patient, given the same options as previously stated. Those who answered they would prescribe antibiotics, oral corticosteroids and/or IL 
hyaluronidase were asked to specify the treatment regimen, given the same options as in the first round.

The final question concerned diagnostic test options, and the responders were asked which exams they wished to perform given the opportunity. The answers included were blood tests for a complete blood count (CBC), chemistry and C-reactive protein, soft tissue ultrasonography, tissue culture, biopsy, or an option where no further tests are required. Responders were given the possibility to choose more than one option.

\section{Statistics}

All responses to questions of the survey are presented as counts and percent of the entire sample. The results are presented in a contingency table, and differences in the distribution of responses between the study groups were evaluated by the chi-square test followed by pairwise comparisons with Benjamini-Hochberg correction. The significance level was defined as $\alpha=0.05$. Analyses were carried out using IBM Corp. Released 2017. IBM SPSS Statistics for Windows, Version 25.0. Armonk, NY: IBM Corp.

\section{Results}

Of the 1120 practitioners who were sent the questionnaire, a total of $334(29.8 \%)$ responded, and their answers were analyzed. The majority of the responders were dentists $(\mathrm{n}=104,31 \%)$, followed by dermatologists and plastic surgeons ( $n=63,19 \%$ and $n=40,12 \%$, respectively), and other physicians $(\mathrm{n}=12738 \%)$.
Over half $(54.5 \%)$ of all responders reported to have more than 5 years of experience with tissue filler injections (Table 1). The number of practitioners with more than 5 years experience was significantly higher for Group B, $77.7 \%$ compared to Groups A and C, both $44.1 \%(p<$ 0.001). Almost one-half (48\%) of the responders reported that they inject 10 syringes (every syringe $=1 \mathrm{~mL}$ ) per week or more in their practice: $68.9 \%$ of Group B injected more than 10 syringes per week compared with $42.2 \%$ of the dentists and $35.7 \%$ of Group C $(p<0.001)$. Notably, only $34.1 \%$ of all responders reported that they keep hyaluronidase on hand at their clinics, and there was no significant difference between the three groups for that parameter.

There were significant differences in the number of encounters with DIRs among the three groups: $48.2 \%$ indicated they had not encountered any, $40.4 \%$ encountered $1-5$ during their career, and $11.4 \%$ encountered more than 5 . $70.9 \%$ of the responders in Group B (dermatologists and plastic surgeons) reported having encountered more than one DIR compared to all the other groups $(p=0.01)$.

Upon assessment of the simulated case, most injectors (74.6\%) initially referred the patient to the emergency department (ED). Interestingly, $91.2 \%$ of dentists compared with $68 \%$ of dermatologists and $65 \%$ of plastic surgeons referred the patient to the ED in the first round of treatment. 30\% of Group C replied they would treat the patient at their clinic. In this simulation, all cases referred to the ED were discharged with the diagnosis of DIR and sent back to the respondent for further management. On

Table I Demographics of Responders

\begin{tabular}{|c|c|c|c|c|c|c|c|c|c|c|}
\hline & & \multicolumn{2}{|c|}{$\begin{array}{l}\text { Dermatologists/ } \\
\text { Plastic Surgeons } \\
(n=103)\end{array}$} & \multicolumn{2}{|c|}{$\begin{array}{l}\text { Internists/GPs/ } \\
\text { Other }(n=\mid 27)\end{array}$} & \multicolumn{2}{|c|}{$\begin{array}{l}\text { Dentists } \\
(n=104)\end{array}$} & \multicolumn{2}{|c|}{$\begin{array}{l}\text { Total } \\
(n=334)\end{array}$} & \multirow[t]{2}{*}{$p$ value } \\
\hline & & $\mathbf{N}$ & $\%$ & $\mathbf{N}$ & $\%$ & $\mathbf{N}$ & $\%$ & $\mathbf{N}$ & $\%$ & \\
\hline Experience, ${ }^{\mathrm{a}}$ years & $\begin{array}{l}<1 \\
I-3 \\
3-5 \\
>5\end{array}$ & $\begin{array}{l}0 \\
11 \\
12 \\
80\end{array}$ & $\begin{array}{l}0.0 \\
10.7 \\
11.7 \\
77.7\end{array}$ & $\begin{array}{l}16 \\
30 \\
25 \\
56\end{array}$ & $\begin{array}{l}12.6 \\
23.6 \\
19.7 \\
44.1\end{array}$ & $\begin{array}{l}2 \\
38 \\
17 \\
45\end{array}$ & $\begin{array}{l}2.0 \\
37.3 \\
16.7 \\
44.1\end{array}$ & $\begin{array}{l}18 \\
79 \\
54 \\
181\end{array}$ & $\begin{array}{l}5.4 \\
23.8 \\
16.3 \\
54.5\end{array}$ & $<0.001$ \\
\hline Number of syringes per week & $\begin{array}{l}<10 \\
10+\end{array}$ & $\begin{array}{l}32 \\
71\end{array}$ & $\begin{array}{l}31.1 \\
68.9\end{array}$ & $\begin{array}{l}81 \\
45\end{array}$ & $\begin{array}{l}64.3 \\
35.7\end{array}$ & $\begin{array}{l}59 \\
43\end{array}$ & $\begin{array}{l}57.8 \\
42.2\end{array}$ & $\begin{array}{l}172 \\
159\end{array}$ & $\begin{array}{l}52.0 \\
48.0\end{array}$ & $<0.001$ \\
\hline Number of DIRs encountered & $\begin{array}{l}0 \\
\mathrm{I}-5 \\
>5\end{array}$ & $\begin{array}{l}30 \\
52 \\
21\end{array}$ & $\begin{array}{l}29.1 \\
50.5 \\
20.4\end{array}$ & $\begin{array}{l}71 \\
44 \\
14\end{array}$ & $\begin{array}{l}55.0 \\
34.1 \\
10.9\end{array}$ & $\begin{array}{l}60 \\
39 \\
3\end{array}$ & $\begin{array}{l}58.8 \\
38.2 \\
2.9\end{array}$ & $\begin{array}{l}161 \\
135 \\
38\end{array}$ & $\begin{array}{l}48.2 \\
40.4 \\
11.4\end{array}$ & $<0.001$ \\
\hline Hyaluronidase at clinic & $\begin{array}{l}\text { No } \\
\text { Yes }\end{array}$ & $\begin{array}{l}68 \\
35\end{array}$ & $\begin{array}{l}66.0 \\
34.0\end{array}$ & $\begin{array}{l}80 \\
49\end{array}$ & $\begin{array}{l}62.0 \\
38.0\end{array}$ & $\begin{array}{l}72 \\
30\end{array}$ & $\begin{array}{l}70.6 \\
29.4\end{array}$ & $\begin{array}{l}220 \\
114\end{array}$ & $\begin{array}{l}65.9 \\
34.1\end{array}$ & 0.394 \\
\hline
\end{tabular}

Note: ${ }^{\text {a}}$ Experience in performing dermal filler injections.

Abbreviations: GP, general practitioner; DIR, delayed inflammatory reaction. 
the other hand, when the patient returned (second encounter), approximately $60 \%$ of all responders reported they would treat the patient at the clinic, however no difference between the groups was observed.

During the first round of treatment, $67 \%$ of responders decided on treating the patient with combined therapies, the most frequent treatment being combined oral antibiotics and oral corticosteroids (14.7\%), along with a combination of oral corticosteroids and IL hyaluronidase (14.7\%) followed by a combination of IL hyaluronidase, topical/IL corticosteroids and oral NSAIDs (13.2\%), and oral antibiotics combined with IL hyaluronidase (11.1\%). Those who opted for monotherapy preferred treating via oral antibiotics $(10.5 \%)$, oral corticosteroids $(9.6 \%)$, or IL corticosteroids $(9 \%)$.

In the second round of treatment, 91\% reported that they preferred combination therapy. The most frequently prescribed treatments in descending order were IL hyaluronidase with topical/IL corticosteroids and oral NSAIDs (22.2\%), IL hyaluronidase with oral antibiotics (21.9\%), and oral antibiotics and oral corticosteroids (21\%). Among those who selected monotherapy for the second round of treatment, the majority $(12.6 \%)$ indicated that they would treat with IL hyaluronidase. Interestingly, $64 \%$ did not dissolve the filler with hyaluronidase in the first episode, whereas $52 \%$ of them did so during the second round.

The majority of responders did not prescribe antibiotics during either round of treatment. The most common antibiotic among those who did prescribe them (39.8\%) was oral amoxicillin/clavulanic acid $875 \mathrm{mg}$ bid for 10 days in the first round, and the most common antibiotic recommended (34.5\%) during the second round was oral ciprofloxacin $500 \mathrm{mg}$ bid for 4-6 weeks. The majority of those who prescribed oral prednisone in the first round recommended either prednisone $40 \mathrm{mg}$ /day for 3 days with slow tapering down (34.8\%) or prednisone $20 \mathrm{mg} /$ day for one week $(34.1 \%)$. For the second round, the majority (31.2\%) prescribed prednisone $40 \mathrm{mg}$ /day for 3 days with slow tapering down. The most commonly prescribed dosage for IL hyaluronidase was 30-100 units per nodule $(51.7 \%)$ in the initial round, and approximately 15 units per nodule in the second round (41.6\%). Over one-half $(53.1 \%)$ of the responders would refer the patient to ultrasonography, $41.4 \%$ would run blood tests (including C-reactive protein levels), and $19.3 \%$ would not recommend any further tests.

\section{Discussion}

DIRs following HA-based filler injections manifest as discolorations, painful nodules, abscesses, induration or tissue hardening and solid edema. ${ }^{5,6}$ Late reactions are mostly defined as ones occurring 14 days to 1 -year postinjection, whereas delayed complications are those that occur one year or longer after treatment. ${ }^{4,7-14}$

Different diagnostic tests to guide the management of DIRs have been suggested and include initially ruling out a fluctuant nodule which may require incision and drainage, from which the content should be sent for bacterial, mycobacterial, and fungal cultures before beginning treatment. ${ }^{4,15-17}$ Other proposed tools consist of PCR, fluorescent in-situ hybridization (FISH), ultrasonography, ${ }^{10}$ blood tests ${ }^{8}$ and in refractory cases biopsy and tissue culture. , $^{1,8,15,16}$

Treatment options for DIRs are diverse, ${ }^{8}$ however the prevalent treatment of choice is oral antibiotics, ${ }^{1,4,13,15-19}$ especially a dual or triple antibiotic regimen. ${ }^{1,4,13,17,18}$ Various regimens have been proposed ie broad-spectrum antibiotics (eg fluoroquinolones) and a macrolide, ${ }^{1,4,16-18}$ taken over a period of several weeks, clarithromycin $500 \mathrm{mg}$ and moxifloxacin $400 \mathrm{mg}$ bid for 10 days, ciprofloxacin 500-750 mg bid for 2-4 weeks, or minocycline $100 \mathrm{mg}$ daily for 6 months. ${ }^{16}$ Other options include oral steroids, IL hyaluronidase, ${ }^{1,12,17}$ IL steroids, ${ }^{1,5,12,13,19,20}$ or the combination of both. ${ }^{5,17,19,20}$ Some authors have suggested reconstitution of corticosteroids with other agents, such as 5-FU, lidocaine, or saline. Alternative options are radiofrequency therapy, ${ }^{17,18}$ laser therapy, ${ }^{18,20}$ human platelet-rich plasma, ${ }^{12}$ or extraction of material. ${ }^{19}$

\section{Conclusions}

The plethora of available approaches for the management of DIRs is reflected by the responses to our survey of Israeli injectors. The authors believe similar results might be obtained would the survey had been performed in other countries around the globe. We, therefore, urge the need to compose a unified, simple, step-wise, comprehensive treatment algorithm for the management of DIRs.

\section{Disclosure}

The authors report no conflicts of interest in this work.

\section{References}

1. Ibrahim O, Overman J, Arndt KA, Dover JS. Filler nodules: inflammatory or infectious? A Review of biofilms and their implications on clinical practice. Dermatol Surg. 2018;44(1):53-60. doi:10.1097/ DSS.0000000000001202 
2. Rohrich RJ, Ghavami A, Crosby MA. The role of hyaluronic acid fillers (Restylane) in facial cosmetic surgery: review and technical considerations. Plast Reconstr Surg. 2007;120(6S):41S-54S. doi:10.1097/01.prs.0000248794.63898.0f

3. American society for aesthetic plastic surgery cosmetic surgery national data bank statistics; 2017. Available from: https://www.plas ticsurgery.org/documents/News/Statistics/2017/plastic-surgerystatistics-report-2017.pdf. Accessed April 21, 2020.

4. Rohrich RJ, Monheit G, Nguyen AT, Brown SA, Fagien S. Softtissue filler complications: the important role of biofilms. Plast Reconstr Surg. 2010;125(4):1250-1256.

5. Lemperle G, Rullan PP, Gauthier-Hazan N. Avoiding and treating dermal filler complications. Plast Reconstr Surg. 2006;118(3S):92S107S. doi:10.1097/01.prs.0000234672.69287.77

6. Kim H, Cho SH, Lee JD, Kim HS. Delayed onset filler complication: two case reports and literature review. Dermatol Ther. 2017;30(5): e12513. doi:10.1111/dth.12513

7. Artzi O, Loizides C, Verner I, Landau M. Resistant and recurrent late reaction to hyaluronic acid-based gel. Dermatol Surg. 2016;42 (1):31-37. doi:10.1097/DSS.0000000000000562

8. Beleznay K, Carruthers JD, Carruthers A, Mummert ME, Humphrey S. Delayed-onset nodules secondary to a smooth cohesive $20 \mathrm{mg} / \mathrm{mL}$ hyaluronic acid filler: cause and management. Dermatol Surg. 2015;41(8):929-939. doi:10.1097/DSS.0000000000000418

9. Monheit GD, Rohrich RJ. The nature of long-term fillers and the risk of complications. Dermatol Surg. 2009;1(35):1598-1604. doi:10.1111/j.1524-4725.2009.01336.x

10. Cassuto D, Sundaram H. A problem-oriented approach to nodular complications from hyaluronic acid and calcium hydroxylapatite fillers: classification and recommendations for treatment. Plast Reconstr Surg. 2013;132(4S-2):48S-58S. doi:10.1097/PRS.0b013e31829e52a7

11. Alsaad SM, Fabi SG, Goldman MP. Granulomatous reaction to hyaluronic acid: a case series and review of the literature. Dermatol Surg. 2012;38(2Part 1):271-276. doi:10.1111/j.1524-4725.2011.02214.x
12. Urdiales-Gálvez F, Delgado NE, Figueiredo V, et al. Treatment of soft tissue filler complications: expert consensus recommendations. Aesthetic Plast Surg. 2018;42(2):498-510. doi:10.1007/s00266-0171063-0

13. Narins RS, Coleman III WP, Glogau RG. Recommendations and treatment options for nodules and other filler complications. Dermatol Surg. 2009;1(35):1667-1671. doi:10.1111/j.15244725.2009.01335.x

14. Lemperle G, Gauthier-Hazan N. Foreign body granulomas after all injectable dermal fillers: part 2. Treatment options. Plast Reconstr Surg. 2009;123(6):1864-1873. doi:10.1097/PRS.0b013e3181858f4f

15. Chiang YZ, Pierone G, Al-Niaimi F. Dermal fillers: pathophysiology, prevention and treatment of complications. J Eur Acad Dermatol Venereol. 2017;31(3):405-413. doi:10.1111/jdv.13977

16. Signorini M, Liew S, Sundaram $\mathrm{H}$, et al. Global aesthetics consensus: avoidance and management of complications from hyaluronic acid fillers - evidence-and opinion-based review and consensus recommendations. Plast Reconstr Surg. 2016;137(6):961. doi:10.1097/ PRS.0000000000002184

17. Hartmann D, Ruzicka T, Gauglitz GG. Complications associated with cutaneous aesthetic procedures. JDDG. 2015;13(8):778-786.

18. Kulichova D, Borovaya A, Ruzicka T, Thomas P, Gauglitz GG. Understanding the safety and tolerability of facial filling therapeutics. Expert Opin Drug Saf. 2014;13(9):1215-1226. doi: $10.1517 / 14740338.2014 .939168$

19. Funt D, Pavicic T. Dermal fillers in aesthetics: an overview of adverse events and treatment approaches. Clin Cosmet Investig Dermatol. 2013;6:295.

20. Ozturk CN, Li Y, Tung R, Parker L, Piliang MP, Zins JE. Complications following injection of soft-tissue fillers. Aesthet Surg J. 2013;33(6):862-877. doi:10.1177/1090820X13493638

\section{Publish your work in this journal}

Clinical, Cosmetic and Investigational Dermatology is an international, peer-reviewed, open access, online journal that focuses on the latest clinical and experimental research in all aspects of skin disease and cosmetic interventions. This journal is indexed on CAS
The manuscript management system is completely online and includes a very quick and fair peer-review system, which is all easy to use. Visit http://www.dovepress.com/testimonials.php to read real quotes from published authors. 